\title{
The Evolution of the Elderly Labor Force Participation and Retirement in Brazil
}

\author{
Bernardo L. Queiroz \\ lanza@cedeplar.ufmg.br \\ Cedeplar-UFMG \\ Matheus L. A. Ferreira \\ matheuslobo.ufmg@gmail.com
}

Preliminary Draft

November 4, 2018 


\begin{abstract}
Background

Population aging and trends in labor force participation rates are creating a considerable impact on the public pension programs around the world. There is a important literature on the time of retirement and during of working life, but not much is known about that in less developed economies nor about future trends.

Objective

In this paper, we investigate the length of retirement in a less developed economy with large public pension program, Brazil. We analyze the evolution of labor force participation and retirement since 1979 and estimate the expected length of retirement from 1979 to 2098 for both males and females.
\end{abstract}

Methods

We use a stochastic model (Lee-Carter) to forecast labor force participation rates. Combining these estimates to UN mortality forecasts. We estimate the expected length of retirement.

\title{
Results
}

We find a steady decline in the labor force participation of young adults and elderly over time, mostly due to access to education and public pension programs, whereas for females we observed a constant increase for the prime-age women. Our findings also indicate that the expected length of retirement might increase from $10 \%$ to over $20 \%$ of Brazilian working lives, as people leave the labor force at early ages and live longer lives.

\section{Conclusions}

These trends, associated with population aging and longer life expectancy reduce the ratio between workers and retirees, affecting the premise of the PAYGO system. Our approach also has public policy implications, since it provides an alternative way to forecast the Brazilian pension budget.

\section{Contribution}

We use a traditional method to forecast mortality to study the evolution of labor force in Brazil. This allows us to estimate the duration of retirement in Brazil and contributes to the policy implementations. 


\section{Introduction}

The aging population increased the concern in relation to the sustainability of the public support programs for the elderly, specially pension programs [Bloom, Canning, and Sevilla, 2003, Bloom and Canning, 2004, Lee and Edwards, 2002, Lee, 2003, Bongaarts, 2004, Li, 2017, Queiroz and Figoli, 2014]. If in the past the family provided a large part of the support for the elderly, today this support comes from programs funded by the public sector and, in some countries, also by the private sector [Costa, 1998]. In general, these programs are very important in order to narrow the difference in income between the elderly and working age individuals and to reduce the poverty rates of the elderly population [Gruber and Wise, 2001]. However, recently, the vast majority of programs have come up against serious fiscal and financial problems [Bongaarts, 2004, Bloom and McNikkon, 2010]. Most of them are based on the PAYGO system, in which contributions from current workers are used to cover the costs of benefits owed to current retirees, giving current workers an expectation of future retirement benefits in return for their current contributions. The balance of such programs has been facing difficulties, especially with the increase in the ratio between beneficiaries and tax payers, population aging and changes in the labor force participation of the elderly [Bongaarts, 2004, Bloom and McNikkon, 2010, De Souza, Queiroz, and Skirbekk, 2018].

Brazil is one of the countries facing such problems [Queiroz, 2017]. Despite unabated interest among researchers in issues pertaining to the impacts of population aging and economic development to the social security sustainability in developed countries [Gruber and Wise, 2005, 2008, Wise, 2004] little is known about these issues in emerging economies[De Souza, Queiroz, and Skirbekk, 2018]. Brazil is one example of an important context for elaborating linkages between population aging and public pension systems. The rapidly aging population presents one of the greatest public policy challenges in Brazil [Turra, Queiroz, and Rios-Neto, 2011, Queiroz and Figoli, 2014]. Compared to other emerging economies, Brazil is distinct for combining a relatively large public sector, spending about $15 \%$ of GDP on public pension programs, with rapidly aging population and declining labor force participation at older ages [Turra, Queiroz, and Rios-Neto, 2011, Queiroz, 2017, Queiroz and Figoli, 2014, De Souza, Queiroz, and Skirbekk, 2018]. The old-age dependency ratio, ratio of the population aged 65 and above to the working-age population, is estimated to be $36 \%$ in 2050, compared to $10 \%$ in 2010 [DeSA, 2017]. These 
changes in population age structure may impose severe pressures on the public sector [Bongaarts, 2004, Miller, Mason, and Holz, 2011, Queiroz and Figoli, 2014].

Several studies investigate and estimated the impacts of changes in population age strucutre and longevity on retirement and public pension programs. However, most of the analysis, especially in the case of Brazil, are not very satisfactory as they use life expectancy at an specific older age or demographic dependency ratio. The dependency ratio as other measures of population aging [Sanderson and Scherbov, 2013, Hammer, Prskawetz, and Feund, 2015] are not the best way to evaluate the impacts of demographic dynamics on pension programs. These measures do not take into accounts changes in the labor force participation, that is, the percentage of workers contributing to the system or the rate of transition into retirement. The support ratio, relates workers contributing in relation to retirees, has also some limitations since most analysis using this metric holds it constant for the future. However, the length of working life has fallen over time, which results from both increases in educational attainment (younger workers) and changes in retirement behavior [Soares, 2010, Queiroz, 2017]. The fall in economic participation for older workers (65 and older) is striking: $22.3 \%$ of them were in the labor force in 2010 compared to 60\% in 1970 [De Souza, Queiroz, and Skirbekk, 2018]. Incorporating changes in labor force participation rates and retirement hazards are fundamental to better understand the dynamics of future trends in public pension programs in countries like Brazil. Over the last half-century, older adults males labor force participation change dramatically [De Souza, Queiroz, and Skirbekk, 2018, Queiroz, 2017, Soares, 2010]. Labor force above age 65 decline from more than $70 \%$ in the 1960's to less than $30 \%$ in 2000 . This implies that, in general, individuals are spending more time receiving pension benefits but this also has important implications to savings behavior, accumulation of capital, public and private transfers [Lee, 2003].

In this paper, we analyze the evolution of labor force participation, for males and females, in Brazil in the last three decades and estimate the expected length of retirement [Lee, 2001]. We argue that this measures provides a better estimate of the impacts of changes in mortality and labor force participation. There is still an important limitation, since we were only able to construct our estimate from cross-sectional data instead of performing a cohort analysis. The expected length of retirement takes into account the retirement hazards and survival probabilities. We also use a stochastic model [Lee and Carter, 1992] to forecast labor force participation rates, from 
2015 to 2100, combine to mortality forecasts from the United Nations and estimate the expected duration of retirement during the same period of time. Lee-Carter is a stochastic method widely used for mortality projection it is a very versatile model and uses historical information to design future scenarios [Booth and Tickle, 2008]. We argue that this is a better measure to evaluate the impact of changes in the population age structure and labor force in the public pension system instead of looking only at trends in the percentage of elderly and labor force participation rates[Li, 2017, Frees, 2006].

The idea to forecast labor force using a stochastic model is an important contribution of this paper. In general, labor force participation rates in Brazil and other countries are projected using deterministic models or without considering past variation trends in activity rates and informality of Brazilian workers, or even population dynamics which directly affects the number of people who could be in the labor force [Rios-Neto and Wajnman, 1994]. To our knowledge, there are no studies or temporal hypothesis, and it is only considered that the total number of workers in the formal sector only varies due to variations of the population by age. There are some papers working with age, period and cohort models but they are also subject to important limitations [Rios-Neto and Hermeto, 1999]. We argue that this approach combine to estimates of population aging are important tools to analyze the sustainability of the Brazilian public pension system. Most of previous research, focus on the expenditures in relation to GDP [Miller, Mason, and Holz, 2011], in the relation between workers contributing to the system and individuals receiving benefits [Queiroz and Figoli, 2014] or simple analyzing trends in the old-age dependency ratios [Rocha and Caetano, 2008]. However, none of these analysis incorporates important changes in the labor force participation of Brazilian workers that happened in the recent decades [De Souza, Queiroz, and Skirbekk, 2018, Queiroz, 2017]

The paper has some important findings. First, we observe a steady decline in the labor force participation of young adults and elderly overtime, mostly due to access to education and public pension programs. We find that the expected length of retirement might increase over time in Brazil as people leave the labor force at early ages and live longer lives. This finding, in conjunction with international comparison, imply an impressive transformation in the Brazilian labor market. Together with population aging and longer life expectancy reduce the ratio between workers and retirees affecting the basic premise of the PAYGO system. Our approach also has public policy implications, since it provides an alternative way to forecast 
the Brazilian public pension system budget. The Brazilian public pension system forecast its costs holding labor force participation constant, what might underestimate future trends. We also consider our estimates to be conservative, since about $20 \%$ of the elderly in Brazil stay in the labor force while receiving pension benefits. Second, the increasing duration of retirement implies that brazilian workers should save an increasing proportion of their working income to support consumption after retirement, however, other studies indicate that most of consumption at older ages in Brazil are financed via public transfers [Turra, Queiroz, and Rios-Neto, 2011].

\section{Overview: The Brazilian Pension System}

The social security of private sector workers in Brazil, as in many other countries, operates under the pay-as-you-go system. In this system, there is an implicit social contract between the different generations. Workers make contributions to social security and resources are used to pay the benefits of current retirees. In the future, when the current generation retires, those who are of working age will make contributions to pay for pensions. And so on, from one generation to another. There is no reserve, collective or individual, to be collected in the future [Stephanes, 1998, Brasil, 2002, Caetano, 2016, 2008, Queiroz and Figoli, 2014].

The social security system in Brazil consists of three main segments: the general system (private sector workers), the system of public servants and various private capitalization systems. In addition, the country also has a large non-contributory system with eligibility determined by the level of income (means-tested) that provides benefits to the low-income population (additional eligibility criteria include age and being physically handicapped).

Most public servants in Brazil have their own defined benefit PAYGO social security system. Although it is small in absolute numbers, when compared to the single (general) system, server pension spending is relatively high, reaching about $4.7 \%$ of GDP in 2015. The program is a complex chain of federal, state and local systems, including special programs for servers in different categories. The benefits are more generous than those of the general system (private sector workers): the replacement rate is higher and the contribution period to receive $100 \%$ of benefits is shorter. The program deficit is high and has been growing in recent years. Recent reforms, notably that of 2003, and the implementation of Funpresp in 2013 will have a positive 
impact on the trajectory of the system in recent years.

The last major reform of the general social security system (RGPS) occurred in the 1988 Constitution. This reform extended social security coverage to most of the previously excluded groups, including rural workers. However, the reform did not generate an equivalent increase in contribution revenues. Other measures have made the system more generous than before: establishing minimum wages as floor, indexing all benefits to the minimum wage, and reducing the minimum retirement age in some cases [Stephanes, 1998, Brasil, 2002, Giambiagi and CASTRO, 2003].

The total benefits were paid, up to 1998, to all workers who had contributed for at least 10 years to the system, had reached the normal retirement age to receive the age benefit (65 for men and 60 for women), or could prove that they were working for a number of years within the length of service retirement program (35 years for men and 30 years for women). In addition, proportional benefits were granted to workers with 30 and 25 years of service, for men and women respectively. The benefits were computed based on the contribution wages of the last 36 months [Caetano, 2016, Barbieri, Ansilieiro, and Costanzi, 2009, Ansileiro and Paiva, 2009].

In 1998, after much debate, a major reform was approved with the aim of helping to reduce the program's fiscal imbalance. The main change was the introduction of a new calculation methodology based on actuarial rules. The system takes into account the history of income, life expectancy at retirement age and introduces a coefficient that reduces the incentives for early retirement. However, a minimum retirement age has not yet been approved for private sector workers [Caetano, 2016, Barbieri, Ansilieiro, and Costanzi, 2009, Ansileiro and Paiva, 2009].. The existence of the social security factor aims to encourage the postponement of retirement, since those who continue working even though they have the necessary contribution time to retire have a greater benefit than if they retire early. This is because the social security factor adapts the benefit value to the contribution time, age and life expectancy [Caetano, 2016, Barbieri, Ansilieiro, and Costanzi, 2009, Ansileiro and Paiva, 2009].

The current retirement situation allows for benefits to be paid to the insured who meets the requirements for retirement by contribution time (35 years of contribution for men and 30 for women) or, instead of the social security factor, it is possible to opt for the Rule Progressive, provided that, until December 2016, she could get the sum of 85 points, if a woman, and 95 points, if a man. From 2017, to exclude the use of the factor, the sum of the 
age and the contribution time would have to be 86, if female, and 96, if male (MPS, 2015). MP 676/2015 limited this schedule until 2022, when the sum for women should be 90 points and 100 points for men.

Despite the fact that the social security factor is responsible for increasing the average retirement age of Brazilians in recent years and decreasing retirement costs for contribution time, this measure is still not efficient if we analyze the long-term projections. Therefore, the introduction of a minimum age to apply for the retirement benefit is one of the main issues addressed in the discussion of pension reform. For, in addition to significantly threatening the sustainability of Social Security, Brazil is one of the only countries that still grants benefits requiring only a certain number of years of contribution [Caetano, 2016].

The introduction of the minimum age seems fundamental to avoid that the relationship between taxpayers and beneficiaries, already badly damaged by the aging of the population, is made even worse by rules that allow early retirements [Caetano, 2016]. In recent years, $63 \%$ of early retirements, men who retire before age 60 and women before age 55, are related to people who represent $40 \%$ of the richest population in the country [Caetano, 2016]

The idea of setting a minimum age for retirement is to increase the potential time for contributions to the social security system, which has a positive effect on Social Security accounts. Although this measure is effective in the short and medium term, because it imposes higher periods of contribution and lower periods of benefit enjoyment, in the long term, as this age is fixed, it does not follow the evolution of life expectancy over time [Caetano, 2016].

\section{Data and Methods}

The main measure to produce estimates of duration of retirement is the labor force participation rate [Costa, 1998]. Labor force participation rate is defined by the International Labor Organization (ILO) as the proportion of the population of some specific age, normally population aged 16 to 65 years, who is either working or actively seeking work to the total population in the same age group. The measure allows to consider those who are already receiving pension benefits, but still in the labor force. We use data from the Brazilian Household Survey (PNAD). PNAD is a nationally representative stratified random sample of the Brazilian population comprised of about 90,000 households similar to the US CPS. The survey consists of cross-sections 
collected annually since 1971, except in 1994 and during censuses years (1980, 1991, 2000 and 2010). The PNAD contains a comprehensive and comparable set of demographic and economic variables, including detailed information on economic activities, contribution for social security programs and whether individuals receive benefits. PNAD micro-data is public available from the National Statistics Office (IBGE) web-site. There was a small change in the definition of labor force participation in PNAD from the 1980s to the 1990s that affected mostly female estimates. In this paper, we do not try to make any adjustment for that change and assume that those are small to impact the results. Thus, for females all estimates were produced from 1992 on.

We calculate labor force participation rates by single ages. The crude estimates for the labor force participation rates present random fluctuations at some ages. In our study, it is far more important to know the global trend and the level of the labor force participation rates than the specific fluctuations occurring at a few ages, so we used a local regression method to get smooth curves. We used the Loess method [Cleveland, 1979, Cleveland and Devlin, 1988] in order to get smooth estimates. The method consists of fitting a low-degree polynomial to a subset of the data at each point of the dataset, in doing so, we do not change the global trend of the curve and we don't have to face the problem caused by the fluctuations observed.

We obtain mortality estimates from the United Nations Population Prospects from 1950 to 2100 [DeSA, 2017]. Mortality estimates and forecast by the United Nations is the more reliable and standardized figures for the analysis. Life-tables for the period of analysis are available in five-year age groups, we used traditional demographic methods, Beers interpolation, to interpolate and obtain mortality rates by single-age groups from ages 20 to 80. The data is public available at: https://esa.un.org/unpd/wpp/ and all codes in $\mathrm{R}$ are available in GitHub.

\subsubsection{Forecasting Labor Force Participation Rates}

In recent years, there is a growing interest in estimating labor force participation in the future and the duration of working life. The main concern is that as population ages, the number of individuals in the current working ages will reduce causing negative impacts on economic development and public programs. One way to reduce those impacts is the extension of the working life. Recent research show the more educated workers are increasing labor force at older ages in the United States and similar trends are observed 
elsewhere. Education dimension has an important role on the future trends of labor force in more developed economies [E, 2015]. The model uses labor force participation by education level combine to population forecasts by education level to obtain the size of the working force in the future. The main assumption is that as population gets more educate labor supply will increase since more educated workers have higher participation. In a different vein, time-series approach can be use to forecast labor force participation [Fuchs and Weber, 2018, Michaud and S., 2008]. The general idea is to relate labor force participation rates and trends to a series of explanatory variables trends [Fuchs and Weber, 2018]. An alternative approach is to estimate the working life expectancy for individuals above certain age [Dudel and Myrskyla, 2017, Dudel, Lopez-Gomes, and Benavides, 2018]. For the United States, the estimates, for the 2010s, on average, someone aged 50 years would still work about 13 years, representing about $43 \%$ of life expectancy at age 20 . In Spain, recent estimates show a decline in the working life expectancy, mainly explained by the financial crisis of 2008 [Dudel, Lopez-Gomes, and Benavides, 2018], but still representing about $50 \%$ of life expectancy at age 50 .

There are two main lines of research about forecasting labor force participation rates in Brazil. The first one uses data from Brazil and other countries and define different patterns of labor force participation rates. From this information and based on the evolution of labor force participation by cohorts in Brazil they try to find a pattern that they might follow based on the observed patterns they observed for other countries [Rios-Neto and Wajnman, 1994]. A second line uses uses age-period-cohort models (APC) from generalized linear models to generate estimates and projections of labor force participation rates in Brazil. The method, however, involves the application of various designs and the need for choosing the best fit criteria. As the authors point out, the over-dispersion problems and sample size makes the choice of the best model tests not very reliable [Rios-Neto and Hermeto, 1999]. In addition, APC models estimates are influenced by the identification problem. In general, the identification problem is not solved simply by restrictions on statistical modeling, but an accounting problem. Once we have the expected effect is the result of age + period + cohort and one of the elements is determined by the other two (ie, age $=$ period - cohort). It is noteworthy that these recent proposals as Yang [Yang, Schulhofer-Wohl, Fu, and Land, 2008] have the same restrictions to identify the traditional APC models [Bell and Jones, 2014]. 


\subsection{Lee-Carter method: forecasting labor force partic- ipation}

We adapted the Lee-Carter method [Lee and Carter, 1992, Lee and Miller, 2001, Lee, 2000] to forecast labor force participation rates in Brazil. There a few studies trying to incorporate the Lee-Carter model to forecast Labor Force Participation [Frees, 2006] with mixed results and a recent paper presented at the PAA meeting by Li Nan using similar approach we use here [Li, 2017].

The method combines a demographic model with time-series method of forecasting. The method involves modeling two-factors age and time - and uses matrix decomposition to extract a single time-varying index of the level of admissions, which is then forecast using a time-series model. The LeeCarter method has been considered a powerful method to forecast mortality due to its precision and simple way to model age distribution of death rates [Lee, 2000, Lee and Miller, 2001, Booth and Tickle, 2008]. The more linear trends in age-specific rates, the more robust is the method [Lee, 2000, Lee and Miller, 2001, Booth and Tickle, 2008]. There are a series of variations to the Lee-Carter model, but we used the more traditional one.

To estimate the model, we need a matrix of $m_{x}$, labor force participation rates and find a solution for Equation 1:

$$
\log \left(m_{x}\right)=a_{x}+b_{x} \times k_{t}+\epsilon_{x, t}
$$

where, $a_{x}$ and $b_{x}$ are parameters to be estimated and $\epsilon$ is a set of random disturbances. The solution of this regression is made by applying the Singular Value-Decomposition approach (SVD) on the log of the historical rates matrix. In the model, $a_{x}$ represents the age pattern of the mortality and labor force participation, $b_{x}$ represents the amount of labor force change at a given age for a unit of yearly total labor force change and $k_{t}$ measures the general level of labor force participation rates.

\subsection{Expected Length of Retirement}

We follow [Lee, 2001] to estimate the duration of retirement (ELRP). It is estimated as a weighted average of life expectancy at each retirement age, where the probability of retiring at age $x$ is the weight of the life expectancy at that age. In other words, if ones retires at age $\mathrm{x}$ the duration of his retirement is the life expectancy at age x. Following a cohort of workers, we 
need to calculate the proportion of the surviving individuals that retire at each particular age [Lee, 2001].

The expected length of retirement is defined [Lee, 2001] as Equation 2 :

$$
E L R P=\sum_{x=20}^{89} S_{x} T_{x} \gamma_{x} *\left[1-\left(0.5 * q_{x}\right)\right]\left[\left(\frac{e_{x}+e_{x+1}}{2}\right)\right]
$$

where ELRP stands for the expected length of retirement at age 20, $S_{x}$ is the probability of remaining alive to age $x, T_{x}$ is the probability of remaining in the labor force until age $x$ conditional on surviving until age $x$, and $g a m m a_{x}$ is the probability of retiring at age $x$ conditional on remaining in the labor force at age $x$. The other terms account for men who die before they leave the labor force, and for those who retire between ages $x$ and $x+1$. gamma is calculated from PNAD data from 1980 to 2015 and from our labor force participation rates projection until the end of the period of analysis. Age specific mortality rates, used to estimate survivorship, are from the United Nations.

We select age 20 as the common age of entry in the labor force. Overtime, mean age at entry in the labor force in Brazil could be lower than that, but we assume a single age over all period of time assuming the small differences would not affect much our results. Choosing a younger age would affect the length of retirement, making it shorter, because of the excess male mortality for young adults, specially during the 1980s and 1990s.

\section{Results}

\subsection{Demographic Dynamics}

The panels of Figure 1 display some of the main features of the demographic changes that have occurred in Brazil over the last decades. Figure 1 also depicts future demographic scenarios. The demographic transition started with mortality improvements in the 1930s, which were followed by fertility declines in the later 1960s. Despite the delayed onset, the demographic transition in Brazil has been characterized by rapid changes. The total fertility rate has reduced by more than half since 1970 (5.3 to 1.9 in 2010) and life expectancy at birth has improved steadily: from 57.5 years in 1970 to 73 years in 2010. From a young quasi-stable age structure in 1970, the age distribution has gradually shifted to an older distribution. Until 2000, 
the most important changes were the decline in the share of the young and a rise in the share of the working age population. Significant increases in the elderly population are expected to occur only in the next decades. Official projections indicate that by 2050, the population aged 65 and older will represent about $20 \%$ of the total population, compared to $3 \%$ in 1970 . These shifts in the age structure can be seen in the dependency ratios, which follow a well documented pattern: the total dependency ratio will decline until 2010 following the decline in the young dependency ratio. The trend will then shift upwards as increases in the old-age dependency ratio becomes more important. This rapid change has an important impact to the public pension program in Brazil, making it very important to analyze labor force participation and retirement trends that could impact the sustainability of the pension program.
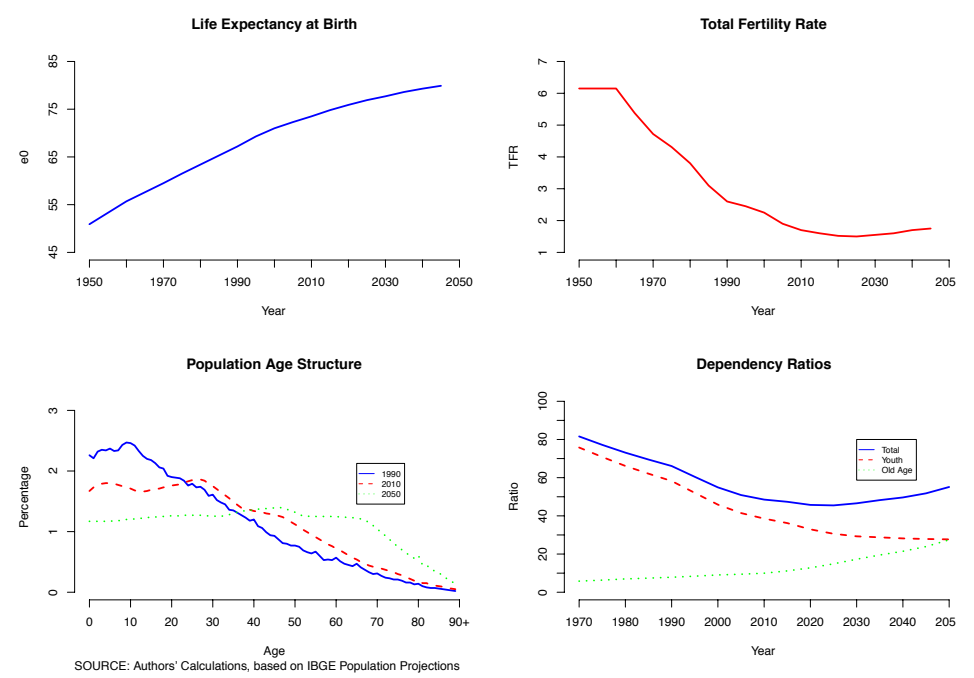

Figure 1: Demographic Transition in Brazil, 1970-2050

Brazil experienced an accelerated decline in infant, child and adult mortality. The average gain in life expectancy at birth between 1950 and 2010 was about 15 years, a much faster process than what happened in developed countries [Borges, 2017, Frana, de Azeredo, Malta, Duncan, Ribeiro, Guimarães, Abreu, Vasconcelos, Carneiro, Teixeira, Camargos, Melo, Queiroz, Schmidt, 
Ishitani, Ladeira, Morais-Neto, Bustamante-Teixeira, Guerra, Bensenor, Lotufo, Mooney, and Naghavi, 2017]. In 1950, life expectancy at birth in the region was around 51 years, reaching 67 years in 1990 and over 70 years in 2010. In Brazil, the mortality rates declined rapidly during a period of 60 years, reducing from 18 death per 1000 individuals in 1940 to 6/1000 in 2010 . The trigger to this rapid improvement in mortality was the sharp decline in infant mortality. During that same period of time, the infant mortality rate in Brazil was estimated at 150 per thousand live births reaching 16 in 2010. In the same fashion, between 1940 and 2010, life expectancy at birth for both sexes also increased, going from 41.53 years to 73.86 years.

Figure 2 displays life expectancy at age 20, for females and females, in Brazil from 1950 to 2100. The estimates show the evolution of life expectancy over time for a long period of time in the country. It is observed a large difference between males and females overtime. UN estimates indicate that in the 1990s and 2000s, an increase in the difference. This variation might be explained by the increase in external causes of deaths for males compare to females. First, is the step decline in the death rates for infant and child in this period. The second one, is the increase in mortality levels for young adults, which is mainly due to the impact of external causes of deaths on the male population. We also observe a decline in mortality levels at older ages that are closely related to an improvement in the health status of males in Brazil in recent decades. The combination of all those changes led to a significant increase in life expectancy at birth in the country in the last few decades. After the 1980s, another shift in the age pattern of mortality is found, characterized by a substantive decline in mortality rates among the elderly (60 or older), especially among those at oldest ages [Campos and do Nascimento Rodrigues, 2004]. There are still significant differences across regions and we are able to identify hotspots of high levels of adult mortality in some areas of the countries. These areas are very related to an increase of mortality for external causes affecting young males [Pereira and Queiroz, 2016] . Reduction in the mortality levels in areas with lower socioeconomic levels might imply better living conditions and overall improvements. 


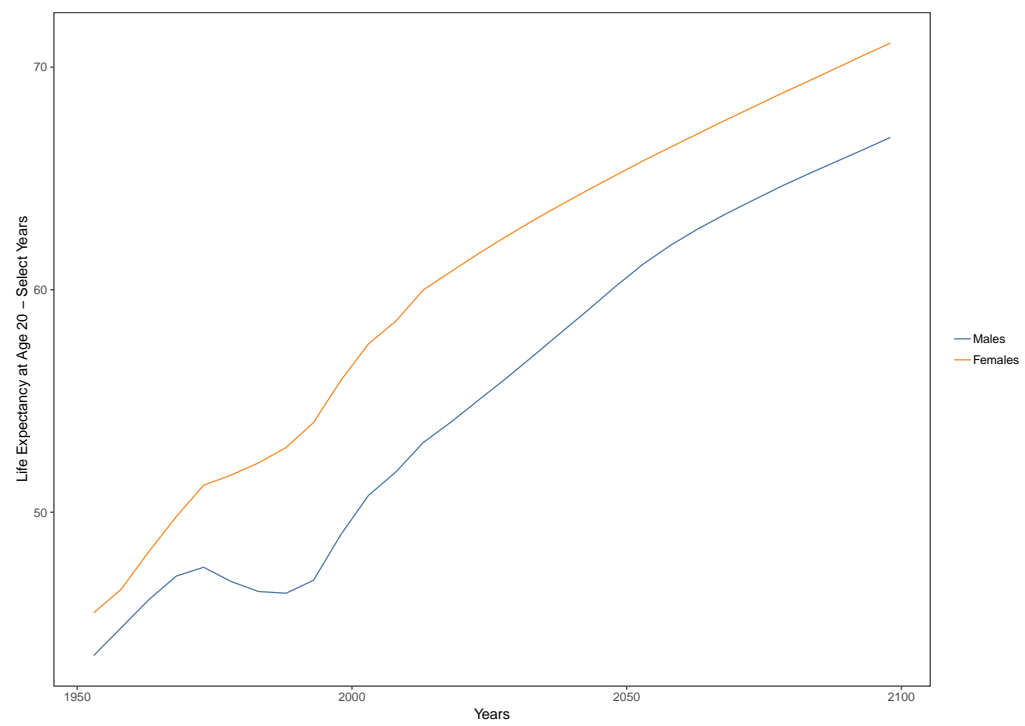

Figure 2: Life expectancy at age 20, Males and Females, Brazil, 1950-2100

Several studies analyzed the causes and the consequences of mortality reduction (focusing on the life expectancy at birth) in Brazil, allowing an advance and better understanding of the transition from high to low mortality levels in the country [Palloni and Souza, 2013, Palloni and Pinto-Aguirre, 2011, Soares, 2007]. According to them, that has been a number of improvements, between 1970 to 2000, which seem to be important determinants of changes in life expectancy and they were not directly correlated with income. The role of increasing education, access to water and sanitation as important factors behind Brazilian mortality decline. The literature suggests a series of possible explanations for the improvement in the health conditions of less developed economies [Palloni and Souza, 2013, Cutler, Deaton, and Lleras-Muney, 2006, Soares, 2007]. The process is associate to changes in the age profile of mortality and causes of death over time. In general, the improvement in health and mortality are associated to improvements in educational level, changes in behavioral and cultural patterns, new technologies and changes in the role of women in the society. 


\subsection{Labor Force Participation Trends}

The trend in labor force participation for Brazilian male workers shows significant changes in the last decades (Figure 3). It is clear that the length of working life declined over time. Labor force participation rates of young males have declined because of the increase in educational attainment. ${ }^{1}$ The rates have also declined for older workers. In 1950 almost $90 \%$ of the population aged sixty to sixty-four years were in the labor force, and this number has declined to less than $60 \%$ in 2010 . The same rate of decline is observed for younger old workers. The fall in economic participation is even greater for older workers, those above sixty-five years of age: less than $30 \%$ of them were in the labor force in 2010 compared to over $60 \%$ in 1950. Figure 4 show the evolution of female labor force, in Brazil, over time same period of time. There are small changes in female labor force at younger and older age groups. Most of the changes are observed in the prime-age groups as labor force of married women increased steadly overtime. However, female labor force is lower than for males and to what is observed in other countries [Rios-Neto and Wajnman, 1994, Souza, Rios-Neto, and Queiroz, 2011, Besamusca, Tijdens, Keune, and Steinmetz, 2015].

We do not show all the Lee-Carter estimates $\left(a_{x}, b_{x}\right.$ and $\left.k_{t}\right)$. We focus our attention on the validation of the method. Figure 5 shows observed and forecasted labor force participation rates in 2013 for males whereas Figure 6 the same analysis for females. We forecast labor force participation rates in 2013 using data from 1980 to 2000. The results are very good based on the limitations to use Lee-Carter method to estimate labor force participation rates. The observed value in 2013 is around the confidence interval estimated for the period. The model did not adjust as well for females due to the rapid changes in female labor force in recent decades, still we were able to obtain a quite robust estimate.

Figure 7 shows the forecasted labor force participation rates by age for males. We show that participation rates for the elderly continue to decline in the country as well at younger ages. This is an improvement compared to what is done by the Brazilian public pension system that forecast pension costs holding labor force participation rates constant at the levels observed in a particular year. Figure 8 shows the forecasted labor force participation rates by age for females.

\footnotetext{
${ }^{1}$ Based on census data I calculated that $95 \%$ of the population aged 10-14 years was in school in 2010 compared to $54 \%$ in 1960.
} 
The previous sections showed that labor force participation of older men fell substantially in Brazil while life expectancy increase rapidly. At the same time the country witnessed a rapid increase in life expectancy. In 1950, life expectancy at birth was less than 51 years, whereas in 2000 it was 70.3 years. In the middle of last century, over $60 \%$ of males aged 65 and above were in the labor force, compared to less than $30 \%$ in 2000. The two simultaneous trends imply that the duration of retirement has increased [Rios-Neto and Wajnman, 1994, Souza, Rios-Neto, and Queiroz, 2011].

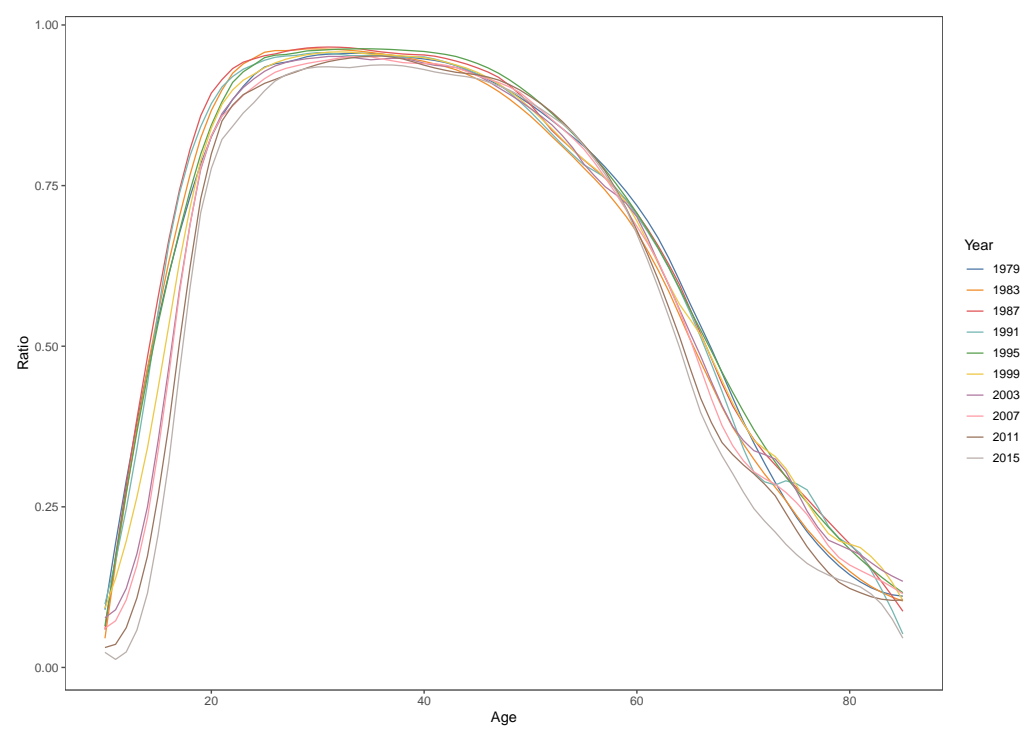

Figure 3: Labor Force Participation Rates, Males, 1980-2015 


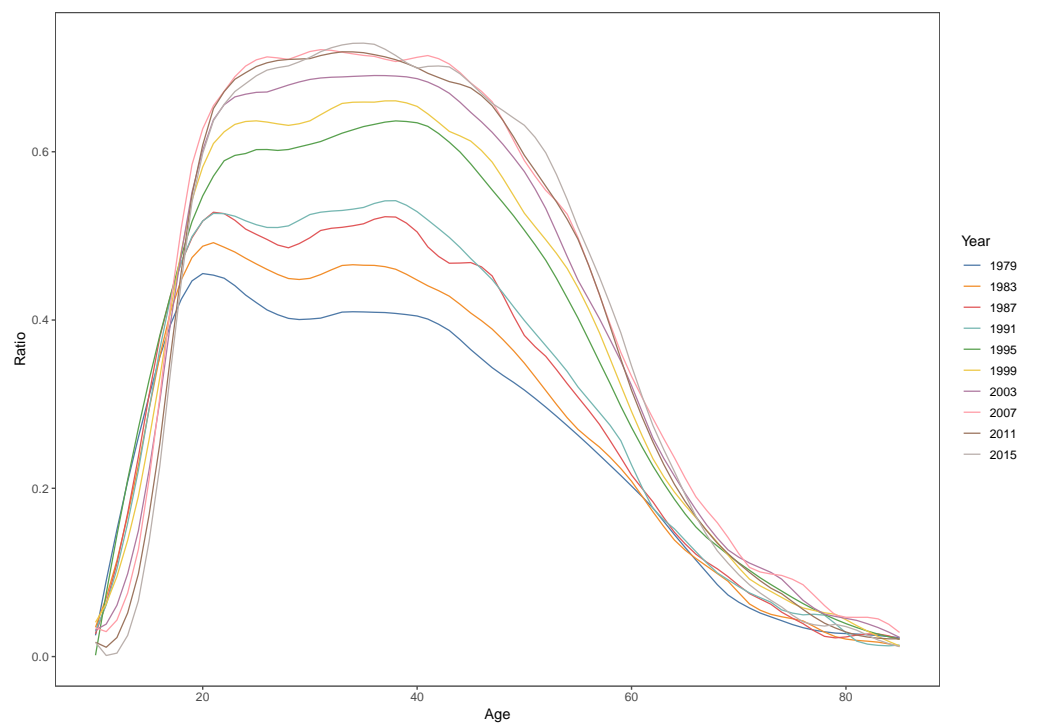

Figure 4: Labor Force Participation Rates, Females, 1980-2015

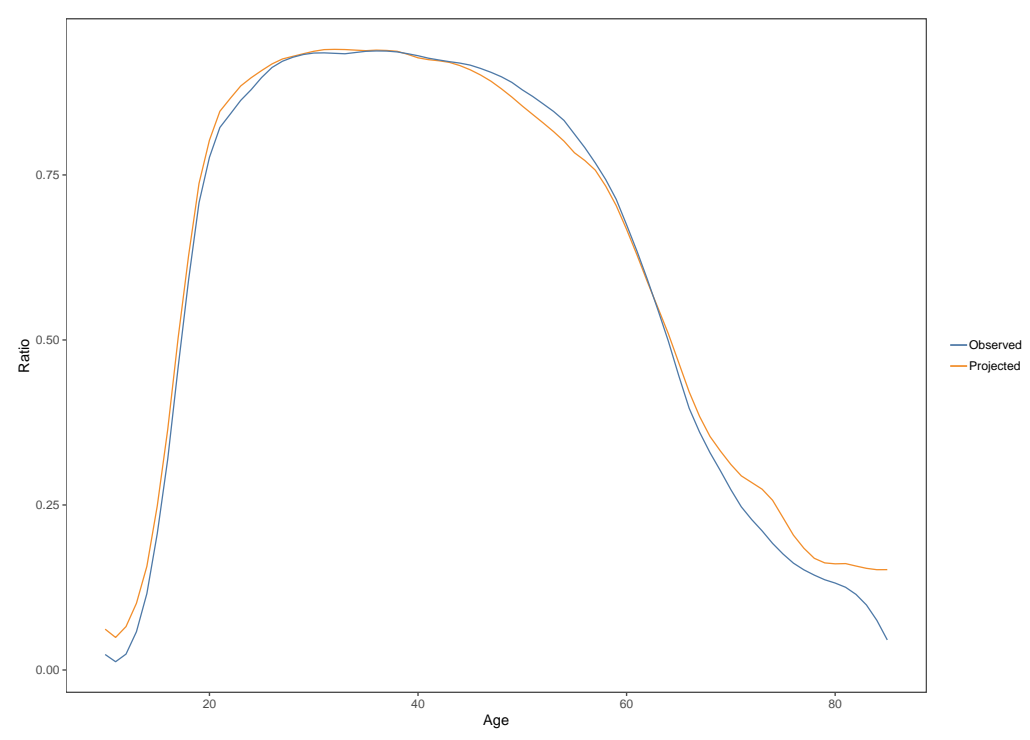

Figure 5: LFPR - Lee-Carter model validation for Males 


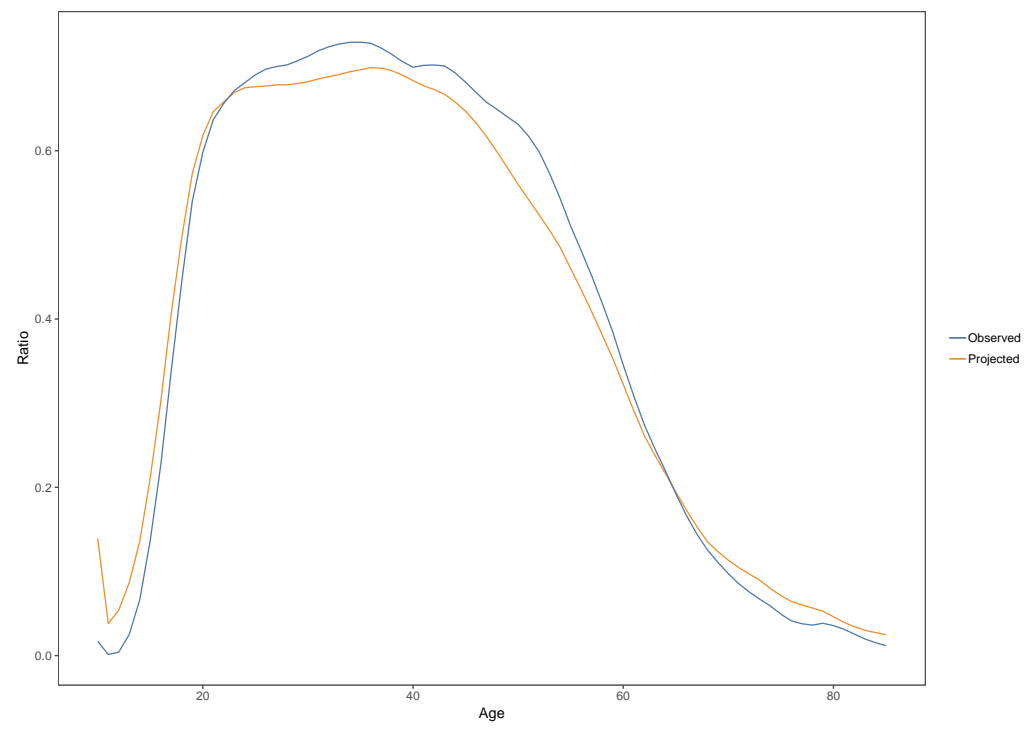

Figure 6: LFPR - Lee-Carter model validation for Females

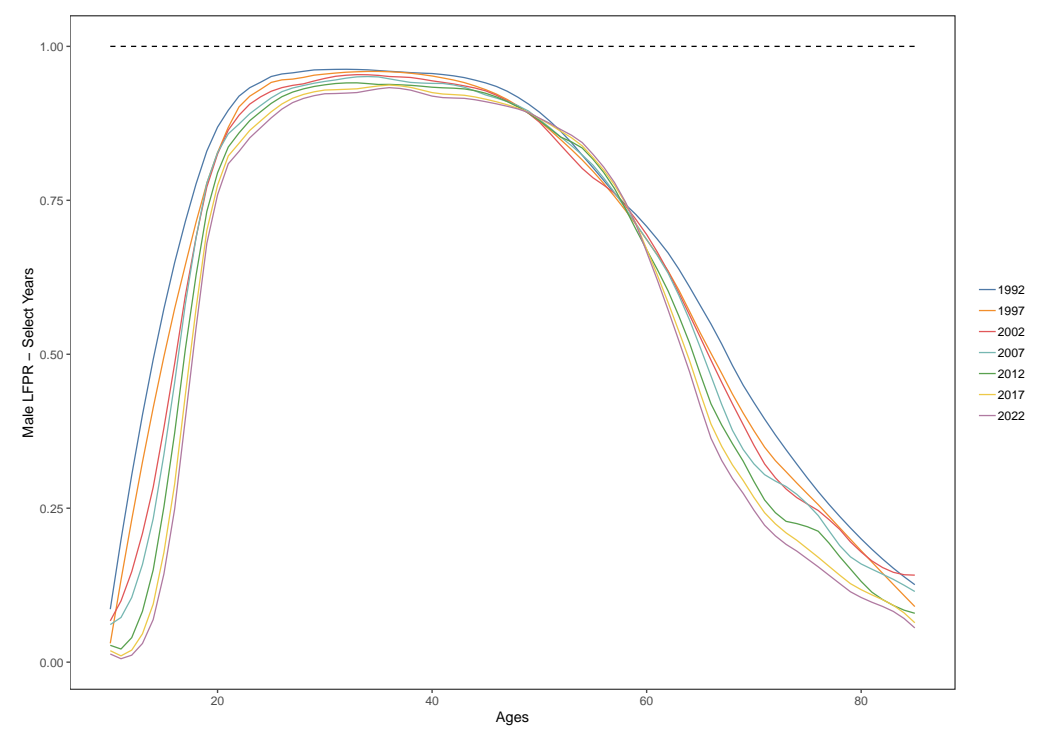

Figure 7: Forecasted Male Labor Force Participation Rates, Brazil, Males, 2015-2050 


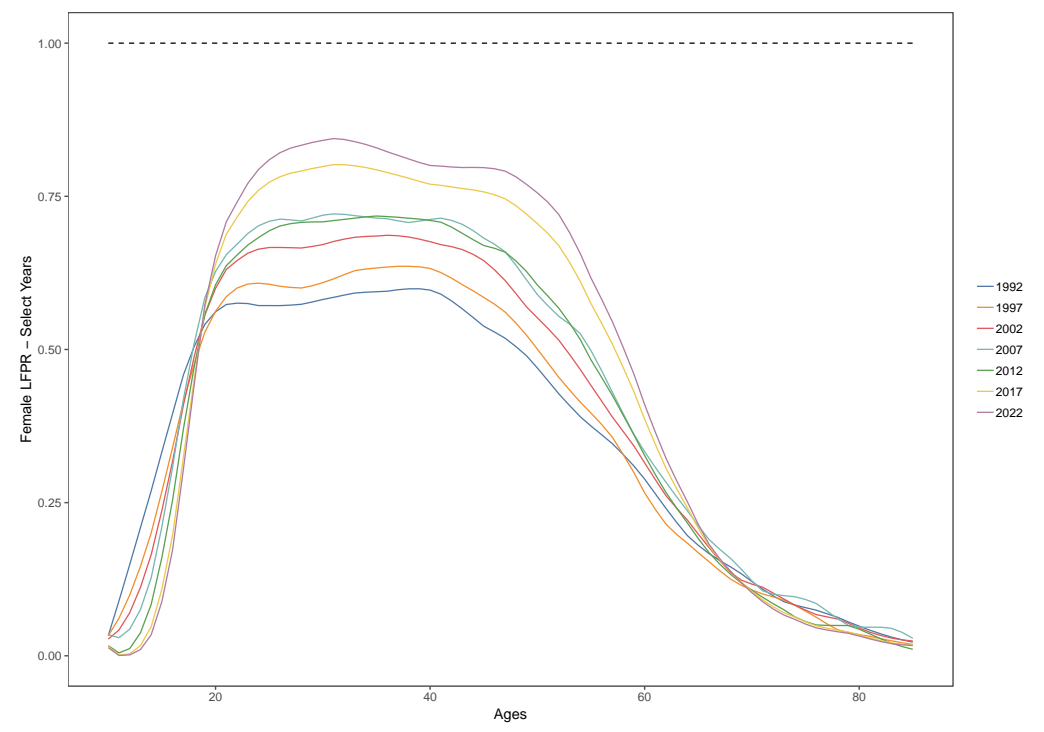

Figure 8: Forecasted Labor Force Participation Rates, Brazil, Females, 20152050

\subsection{Expected Length of Retirement in Brazil: 1980- 2100}

Changes in length of retirement have important implications for economic issues, for instance in savings and public pension finances [Lee, 2001]. Despite its relevance, very few studies have tried to estimate such a measure [Lee, 2001]. The author shows that in the United States, retirement years have increased six-fold since 1850 and now represent $30 \%$ of a worker's productive years. In Brazil, the rapid changes in life expectancy and labor force participation rates can have important implications for the economy. These two events combined to increase the percentage of one's life spent in retirement. The length of retirement can be estimated under two assumptions. The first one it assumes that an individual assesses the length of his retirement based on current levels (period data) of labor force participation and mortality. In the second one, individuals adjust their expectations based on their cohort experience. The first, a synthetic cohort approach, gives us a lower bound of the estimates. For lack of cohort data in Brazil, and lack of good labor force participation projections, I can only calculate the period estimates. 


\begin{tabular}{cccc}
\hline Year & Expected Retirement & $e_{20}$ in years & \% of Life Retired \\
\hline $\mathbf{1 9 8 3}$ & 4.17 & 52.22 & 8 \\
$\mathbf{2 0 0 3}$ & 8.99 & 57.56 & 15.63 \\
$\mathbf{2 0 2 3}$ & 14.42 & 61.62 & 23.41 \\
$\mathbf{2 0 4 3}$ & 16.58 & 64.49 & 25.71 \\
$\mathbf{2 0 6 3}$ & 18.17 & 67.02 & 27.12 \\
$\mathbf{2 0 8 3}$ & 19.68 & 69.36 & 28.38 \\
$\mathbf{2 0 9 3}$ & 20.80 & 70.52 & 28.98 \\
\hline
\end{tabular}

Table 1: Life Expectancy at 20, Expected Length of Retirement and Percentage of Working Life as Retired, Females, Brazil

Table 1 presents the period estimates for the Expected Length of Retirement (ELRP) and their ratios to life expectancy at age 20 for Females. Not surprisingly, improvements in life expectancy and decline in labor force participation results in the extension of retirement years. The ELRP at age 20 went from 4.17 years in 1980 to 10.23 years in 2025 , reaching 16.98 years in 2095. Table 2 presents the period estimates for the Expected Length of Retirement (ELRP) and their ratios to life expectancy at age 20 for Males. The duration of retirement, for males, went from 4.17 years in 1980 to 14.42 in 2025 and reached 20.80 years in 2095 . The results indicate that the duration of retirement as percentage of life expectancy at age 20 is increasing rapidly. In 1980, males and females spent less than $10 \%$ of their life expectancy at age 20 in retirement, $9.51 \%$ for males and $8 \%$ for females. In 2025 , we estimate that the duration of retirement will more than double reaching $16 \%$ for males and $23 \%$ for females. In the last period of the projection analysis, duration of retirement for males will reach $23 \%$ and for females almost $30 \%$ of the life expectancy at age 20 


\begin{tabular}{cccc}
\hline Year & Expected Retirement & $e_{20}$ in years & \% of Life Retired \\
\hline $\mathbf{1 9 8 3}$ & 4.96 & 46.44 & 9.51 \\
$\mathbf{2 0 0 3}$ & 6.98 & 50.76 & 12.14 \\
$\mathbf{2 0 2 3}$ & 10.23 & 55.03 & 16.61 \\
$\mathbf{2 0 4 3}$ & 12.37 & 59.09 & 19.19 \\
$\mathbf{2 0 6 3}$ & 14.63 & 62.74 & 21.56 \\
$\mathbf{2 0 8 3}$ & 16.62 & 65.20 & 22.98 \\
$\mathbf{2 0 9 3}$ & 16.98 & 66.29 & 23.58 \\
\hline
\end{tabular}

Table 2: Life Expectancy at 20, Expected Length of Retirement and Percentage of Working Life as Retired, Males, Brazil, 1980-2100

The changes in the duration of retirement are explained by changes in labor force participation, transition to retirement and the evolution of life expectancy [Lee, 2001, Coile, 2015, Dudel, Lopez-Gomes, and Benavides, 2018]. We show how changes in mortality and labor force participation rates impact the expected length of retirement. This estimate is made by calculating ELRP assuming that either mortality or labor force participation rates remain constant at the 1980 levels. For example, to examine the relative contribution of mortality decline, we calculate the ELRP using varying retirement rates and the 1980 death rates. This counter factual estimate shows how large the increase in ELRP would be during the period had there been only change in labor force participation rates. To estimate the contribution of changes in retirement, we perform similar analysis holding retirement rates constant at the 1980 levels.

Figure 9 and Figure 10 shows the estimates for the baseline scenario and the two counter factual analysis from 1980 to 2100, for males and females, respectively. We find that the decline in mortality levels is the more important factor in determining the changes in ELRP, as compared to changes in mortality. First, we hold labor force participation rates constant at 1980 levels. On one hand, I find that the ELRP would be shorter if there were no changes in labor force participation rates. On the other hand, improvements in mortality explains most of the variation in the ELRP. This result reflect the impressive decline in labor force participation discussed before and the rapid mortality transition. 


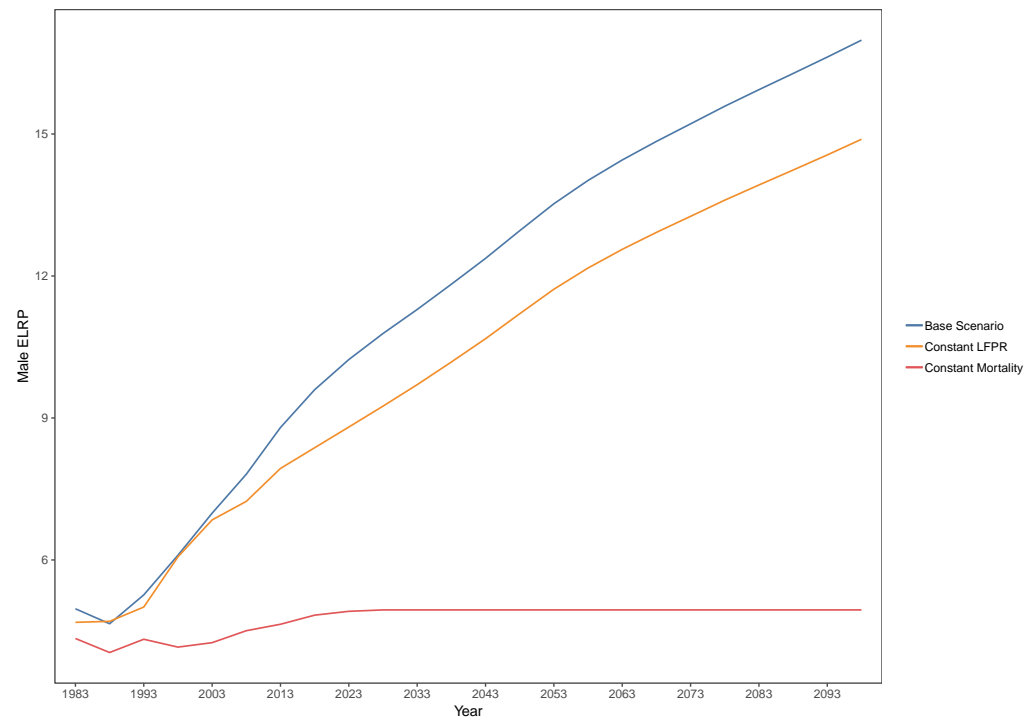

Figure 9: Expected Length of Retirement, Males, Brazil, 1980-2100

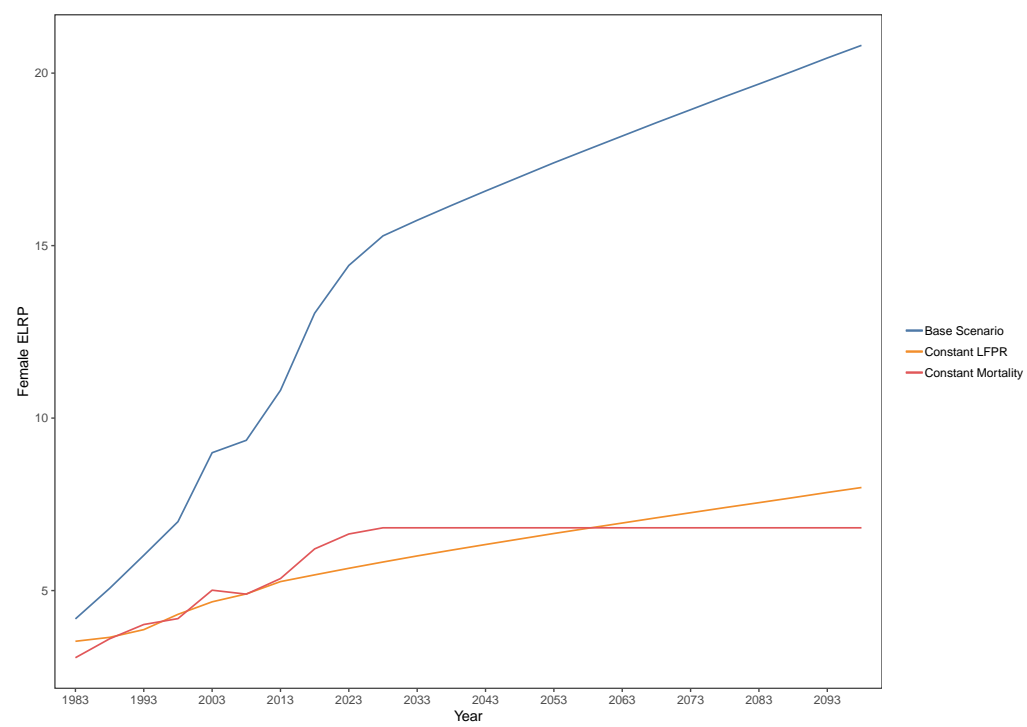

Figure 10: Expected Length of Retirement, Females, Brazil, 1980-2100 


\section{Conclusion}

The rapid process of population aging will have huge impacts on the sustainability of the Brazilian pension system. The increase in the old age dependency ratio means a larger number of beneficiaries will depend on a smaller number of workers. The demographic problem is not the sole issue in this matter. There is also a strong downward trend in labor force participation at older ages and a decline in retirement ages. In addition to that informality in the brazilian labor market is very high thus affecting the number of workers that contribute to the system. The combination of early retirement and labor market informality has increased the dependency ratio more than would be predicted by changes in population age structure. Using the Lee-Carter model, we forecast that labor force participation rates of older men, that fell fell significantly between 1950 and 2010, are going to decline until 2050. Recent evidence for more developed economies show an increase in labor force of the elderly in recent years ([Blundell, French, and Tetlow, 2016]) closely related to policy changes that increase minimum age of retirement, but there are another set of behavioral issues that might impact the trend [Behaghel and Blau, 2012]. However, there is still need to better understand the causes of recent rises in retirement age. In the case of Brazil, given current public pension regulations, we observe a small increase in the labor force participation of the more educated elderly, but with almost no impact on the general declining trend. We show that labor force participation for older workers declined rapidly overtime. This goes in line with other research in the area [Queiroz, 2017, De Souza, Queiroz, and Skirbekk, 2018] showing that despite improvements in health conditions labor supply of the elderly decline in Latin America. Also, there is a negative relation between economic development and labor supply of the elderly, as national income grows labor force participation declines.

We estimate the duration of retirement as a novel measure to estimate the impact of demographic changes on public pension programs. Generally, analysis relating demographic changes and pension programs rely on demographic dependence ratios and support ratios. However, those measures do not capture well enough trends in labor force participation and retirement behavior. The metric used here combines survival functions and labor force participation rates forecasted until 2050 and provides with an estimate of the amount of time one will spend in retirement from certain age. The results suggests for the importance of savings - considering individual, public and 
familial - a worker should consider to maintain her consumption level after leaving the labor force. If in the early 1980s the duration of retirement in Brazil was below $10 \%$ of life expectancy at age 20, at the turn of the century, 20 years later, it reached $15 \%$ and we forecast it to be about $25 \%$ of ones life in 2050. Compared to other countries, we find that in the United States the length of retirement in 1980 was $21 \%$ and increased to $24 \%$ in 1990 . Most of the change was driven by mortality decline during the twenty century. This trend indicates that individuals, and public pension programs, should consider an increasing proportion of their working income as financial reserve to fund consumption in retirement. These changes also provide some insights for the discussion of public pension reform in Brazil. Increase retirement ages could create incentives to raise saving rates in the country, but there is little evidence in the country of this impact. In fact, there are some research showing that the size of public pension program in Brazil creates incentives for not saving.

These results are the lower-bound of changes in ELRP. We obtain our estimates from a series of cross-sectional surveys and given data limitations are not able to produce estimates by birth cohorts. Therefore, we might be missing important changes in mortality improvements and labor supply that might affect different cohorts differently. It is clear that age-specific labor force participation rates are declining and life expectancy is rising for younger cohorts, meaning that younger generations will have a longer length of retirement. The increase in ELRP indicates that workers should save more of their income to smooth their consumption over the life-cycle. It also suggests that pressures on the Brazilian pension system will be greater in the near future, as suggested elsewhere [Queiroz and Figoli, 2014, Caetano, 2016]. The results has also important implications for individuals savings. If workers decide on their savings based on the duration of retirement, they should be saving more to sustain a certain consumption level after leaving the labor force.

In recent years, there are important discussion regarding changes to the brazilian public pension program. One of the main issues is the implementation of an unique minimum retirement age for all workers. Minimum retirement age would have positive impacts on savings behavior but also on the sustainability of the Brazilian pension program. Our estimates suggest that there is a combination of changes in labor force and mortality that affect the duration of retirement. Over the past few years, we find, for males, that the decline in labor force participation rates have 


\section{References}

David Bloom, David Canning, and Jaypee Sevilla. The demographic dividend: a new perspective on the economic consequences of population change. Rand, 2003.

David Bloom and David Canning. Global demographic change: Dimensions and economic significance. Technical report, National Bureau of Economic Research, 2004.

Ronald D Lee and Ryan Edwards. The fiscal effects of population aging in the us: Assessing the uncertainties. 1(1):141-180, 2002.

Ronald D Lee. Intergenerational transfers and the economic life cycle: A cross-cultural perspective. na, 2003.

John Bongaarts. Population aging and the rising cost of public pensions. Population and Development Review, 30(1):1-23, 2004.

$\mathrm{N}$ Li. Is the problem of population aging real? an answer obtained from the labor force participation of the g7 countries. In Annual Meeting of the Population Association of America, page 20, United States, April 2017.

Bernardo Queiroz and Moema Figoli. Population aging and the rising costs of public pension in brazi. In Tom Reilly, editor, Pensions: Policies, New Reforms and Current Challenges. Nova Science Publishers, 2014.

Dora L Costa. The evolution of retirement. University of Chicago Press, 1998.

Jonathan Gruber and David Wise. An international perspective on policies for an aging society. Technical report, National bureau of economic research, 2001.

David Bloom and Rod McNikkon. Social security and the challenge of demographic change. International Social Security Review, 63(4):3-21, 2010 .

L De Souza, B Queiroz, and V Skirbekk. Trends in health and retirement in latin america: Are older workers healthy enough to extend their working lives? The Journal of the Economics of Ageing, 2018. 
B Queiroz. Public pensions, economic development, and the labor force participation of older adults in latin america in 1990-2010. International Journal of Population Studies, 1(3):121-137, 2017.

Jonathan Gruber and David Wise. Social security programs and retirement around the world: Micro-estimation. ILR Review, 58(2):86, 2005.

Jonathan Gruber and David Wise. Social security and retirement around the world. University of Chicago Press, 2008.

David Wise. Social security provisions and the labor force participation of older workers. Population and Development Review, 1(1):176-205, 2004.

Cassio Turra, Bernardo Queiroz, and Eduardo Rios-Neto. Idiosyncrasies of intergenerational transfers in brazil. In Andrew Mason Ronald Lee, editor, Population Aging and the Generational Economy. Edward Elgar, 2011.

United Nations DeSA. World population prospects: The 2017 revision, methodology of the united nations population estimates and projections. Population Division of the Department of Economic and Social Affairs of the United Nations, 2017.

Ttim Miller, Carl Mason, and Maurizio Holz. The fiscal impact of demographic change in ten latin american countries: projecting public expenditures in education, health, and pensions. In Population aging: is Latin America ready, pages 233-272. World Bank, 2011.

W Sanderson and S Scherbov. The characteristics approach to the measurement of population aging. Population and Development Review, (39(4)): 673-685, 2013.

B Hammer, A Prskawetz, and I Feund. Production activities and economic dependency by age and gender in europe: A cross-country comparison. The Journal of the Economics of Ageing, (5):86-97, 2015.

Rodrigo Soares. Aging, retirement and the labor market in brazil. Technical report, World Bank Seminar on Aging in Brazil, 2010. Paper.

Chulhee Lee. The expected length of male retirement in the united states, 1850-1990. Journal of Population Economics, 14(4):641-650, 2001. 
Ronald D Lee and Lawrence R Carter. Modeling and forecasting us mortality. Journal of the American statistical association, 87(419):659-671, 1992.

Heather Booth and Leonie Tickle. Mortality modelling and forecasting: A review of methods. Annals of actuarial science, 3(1-2):3-43, 2008.

Edward Frees. Forecasting labor force participation rates. Journal of Official Statistics - Stockholm, 22(3), 2006.

Eduardo Rios-Neto and Simone Wajnman. Participação feminina no mercado de trabalho no brasil: alternativas para projeções de níveis e padrões. Pesquisa e Planejamento Economico, 1994.

Eduardo Rios-Neto and Ana Hermeto. Aplicação de um modelo de idadeperíodo-coorte para a atividade econômica no brasil metropolitano. Pesquisa e Planejamento Economico, 1999.

Romero Rocha and Marcelo Caetano. O sistema previdenciário brasileiro: uma avaliação de desempenho comparada. In Previdência Social no Brasil: debates e desafios. IPEA, 2008.

Reinold Stephanes. Reforma da Previdncia. 1998.

Brasil. Livro Branco da da Previdência Social. 2002.

Marcelo Caetano. O fim do fator previdencirio e a introduo da idade mnima: questes para a previdncia social no brasil. Technical report, IPEA, 2016. Texto para Discusso.

Marcelo Caetano. Previdencia Social no Brasil: desafios e debates. Instituto de Pesquisa Econômica Aplicada (Ipea), 2008.

Fabio Giambiagi and Lavínia Barros de CASTRO. Previdência social: diagnósticos e propostas de reforma. Revista do BNDES, 10(19):265-292, 2003 .

Carolina Barbieri, Graziela Ansilieiro, and Rogerio Costanzi. A expanso da cobertura previdenciria no brasil. In Previdncia Social: reflexes e desafios, pages 69-111. Ministrio da Previdncia Social, 2009.

Graziela Ansileiro and Luiz Paiva. The recent evolution of social security coverage in brazil. International Social Security Review, (61):1-28, 2009. 
W. Cleveland. Robust locally weighted regression and smoothing scatterplots. Journal of the American Statistical Association, 74(368):829-836, 1979.

W Cleveland and S Devlin. Locally weighted regression: an approach to regression analysis by local fitting. Journal of the American Statistical Association, 83(403):596-610, 1988.

Loichinger E. Labor force projections up to 2053 for 26 eu countries, by age, sex, and highest level of educational attainment. Demographic Research, (32):443-86, 2015.

S Fuchs and D Weber. Stochastic forecasting of labor supply and population: An integrated model. Population Research and Policy Review, 37:33-58, 2018.

P Michaud and Rohwedder S. Forecasting labor force participation and economic resources of the early baby boomers. Michigan Retirement Research Center Research Paper No. WP 2008-175, 2008.

C Dudel and M Myrskyla. Working life expectancy at age 50 in the united states and the impact of the great recession. Demography, 6(54):2101-2123, 2017.

C Dudel, M Lopez-Gomes, and F Benavides. The length of working life in spain: Levels, recent trends, and the impact of the financial crisis. European Journal of Population, pages 1-23, 2018.

Y Yang, S Schulhofer-Wohl, W Fu, and K Land. The intrinsic estimator for age-period-cohort analysis: What it is and how to use it. American Journal of Sociology, 2008.

A Bell and K Jones. Another'futile quest'? a simulation study of yang and land's hierarchical age-period-cohort model. Demographic Research, 2014.

Ronald Lee and Tim Miller. Evaluating the performance of the lee-carter method for forecasting mortality. Demography, 2001.

Ronald Lee. The lee-carter method for forecasting mortality, with various extensions and applications. North American actuarial journal, 4(1):80-91, 2000 . 
Gabriel Borges. Health transition in brazil: regional variations and divergence/convergence in mortality. Cadernos de Sade Pblica, (33):1-15, 2017.

Elizabeth Frana, Valéria Maria de Azeredo, Deborah Carvalho Malta, Bruce B. Duncan, Antonio Luiz P. Ribeiro, Mark D. C. Guimarães, Daisy M.X. Abreu, Ana Maria N. Vasconcelos, Mariângela Carneiro, Renato Teixeira, Paulo Camargos, Ana Paula S. Melo, Bernardo L. Queiroz, Maria Inês Schmidt, Lenice Ishitani, Roberto Marini Ladeira, Otaliba L. MoraisNeto, Maria Tereza Bustamante-Teixeira, Maximiliano R. Guerra, Isabela Bensenor, Paulo Lotufo, Meghan Mooney, and Mohsen Naghavi. Causespecific mortality for 249 causes in brazil and states during 19902015: a systematic analysis for the global burden of disease study 2015. Population Health Metrics, (15):39, 2017.

Nelson Otávio Beltrão Campos and Roberto do Nascimento Rodrigues. Ritmo de declínio nas taxas de mortalidade dos idosos nos estados do sudeste, 1980-2000. Revista Brasileira de Estudos de População, 21(2):323-342, 2004 .

Fabiano Neves Alves Pereira and Bernardo Lanza Queiroz. Differences in mortality in brazilian youth: the importance of household socioeconomic factors and living conditions in brazilian municipalities and states. Cadernos de saude publica, 32(9), 2016.

Alberto Palloni and Laetícia Souza. The fragility of the future and the tug of the past: Longevity in latin america and the caribbean. Demographic research, 29:543, 2013.

Alberto Palloni and Guido Pinto-Aguirre. Adult mortality in latin america and the caribbean. In International handbook of adult mortality, pages 101-132. Springer, 2011.

Rodrigo Soares. Soares, rodrigo r. "on the determinants of mortality reductions in the developing world. Population Development Review, (33):247-287, 2007.

David Cutler, Angus Deaton, and Adriana Lleras-Muney. The determinants of mortality. Journal of economic perspectives, 20(3):97-120, 2006.

Laetícia Rodrigues de Souza, Eduardo Luiz Gonçalves Rios-Neto, and Bernardo Lanza Queiroz. The relationship between childbirth and women's 
labor in brazil. Revista Brasileira de Estudos de População, 28(1):57-79, 2011.

Janna Besamusca, Kea Tijdens, Maarten Keune, and Stephanie Steinmetz. Working women worldwide. age effects in female labor force participation in 117 countries. World Development, 74:123-141, 2015.

Courtney Coile. Economic determinants of workers retirement decisions. Journal of Economic Surveys, (29):830-853, 2015.

Richard Blundell, Eric French, and Gemma Tetlow. Retirement incentives and labor supply. In Handbook of the economics of population aging, volume 1, pages 457-566. Elsevier, 2016.

Luc Behaghel and David M Blau. Framing social security reform: Behavioral responses to changes in the full retirement age. American Economic Journal: Economic Policy, 4(4):41-67, 2012. 